\title{
Epoxidation of 2-buten-1-ol over Ti-MCM-41 and Ti-MCM-48 titanium silicalite catalysts
}

\author{
Agnieszka Wróblewska, Ewelina Lawro, Eugeniusz Milchert \\ Szczecin University of Technology, Faculty of Technology and Chemical Engineering, ul. Pułaskiego 10, 70-322 Szczecin, \\ Poland, e-mail: Agnieszka.Wroblewska@ps.pl
}

\begin{abstract}
The results of the epoxidation of 2-buten-1-ol with $30 \mathrm{wt} \%$ hydrogen peroxide have been presented. As a solvent methanol was used. The process was carried out over the titanium silicalite catalysts: Ti-MCM-41 and Ti-MCM-48. The influence of temperature $\left(20-120^{\circ} \mathrm{C}\right)$, the molar ratio of CRA/ $\mathrm{H}_{2} \mathrm{O}_{2}(5: 1-5: 1)$, methanol concentration $(5-90 \mathrm{wt} \%)$, catalyst concentration $(0.1-5.0 \mathrm{wt} \%)$ and the reaction time (30 $300 \mathrm{~min}$ ) was investigated. The obtained results were used for the determination of optimum conditions of running the epoxidation process of 2-buten-1-ol.
\end{abstract}

Keywords: epoxidation, 2,3-epoxybutan-1-ol, Ti-MCM-41, Ti-MCM-48.

Presented at VII Conference Wasteless Technologies and Waste Management in Chemical Industry and Agriculture, Międzyzdroje, 12 - 15 June, 2007.

\section{INTRODUCTION}

The epoxidation of 2-buten-1-ol with a $30 \mathrm{wt} \%$ hydrogen peroxide was carried out with the application of the titanium silicate catalysts: Ti-MCM-41 and Ti-MCM-48. The former catalyst has a hexagonal structure, which is characterized by long, non-branched one dimensional channels with uniform diameters. The pares diameter of this catalyst amounts to $4.9-7.6 \mathrm{~nm}^{1}$, the specific surface area reaches $1200 \mathrm{~m}^{2} / \mathrm{g}$, and the thickness of the pore walls is located in the range of $0.8-1.2 \mathrm{~nm}^{2}$. The TiMCM-48 structure (gyroide structure) has a three-dimensional system of channels, the diameter of which varies over the range of $1.5-10 \mathrm{~nm}^{2}$, and the pore wall thickness amounts to $0.8-1.0 \mathrm{~nm}^{3,4}$.

Traditional methods of the epoxide synthesis rely on the intramolecular cyclization of chlorohydrins with the use of aqueous alkaline solutions or on the alkene epoxidation with per-acids. There have been developed new directions in the synthesis of this group of compounds in recent years. They rely on the elimination of organic wastes, the by-products difficult to manage and on the limitation of the quantity of the generated sewage. These objectives were achieved through the catalytic processes of the oxidation of olefinic compounds with organic hydroperoxides or hydrogen peroxide.

The major product in the epoxidation process of 2buten-1-ol (crotyl alcohol) is 2,3-epoxybutan-1-ol (EB), the compound having numerous applications. 2,3Epoxybutan-1-ol is applied for the preparation of many products belonging to the family of $\beta$-lactame antibiotics such as tyrosine, erythromycine and tienamycine ${ }^{5}$. This compound is also applied in the production of drugs utilized in the therapy of HIV virus infection $\mathrm{B}^{6-9}$.

\section{EXPERIMENTAL}

Ti-MCM-41 catalyst was prepared by the method described by Grün et al. ${ }^{10}$, whereas the Ti-MCM-48 catalyst, according to the method described by Schumacher et al. ${ }^{11}$. The epoxidation of 2-buten-1-ol with a $30 \mathrm{wt} \%$ hydrogen peroxide over Ti-MCM-41 and Ti-MCM-48 catalyst was carried out in an autoclave made of 1H18N9T stainless steel, checked under the pressure of $9.8 \mathrm{MPa}$ and equipped with a Teflon insert of $7 \mathrm{~cm}^{3}$ capacity. The influence of the following technological parameters: temperature $20-$ $120^{\circ} \mathrm{C}$, the molar ratio of 2-buten-1-ol/ $\mathrm{H}_{2} \mathrm{O}_{2}$ 0.5:1 - 5:1, solvent (methanol) concentration $5-90 \mathrm{wt} \%$, catalyst concentration $0.1-5.0 \mathrm{wt} \%$ and the reaction time $30-$ $300 \mathrm{~min}$ was investigated. The initial parameters of the studies were as follows: the temperature of $20^{\circ} \mathrm{C}$, the molar ratio of 2-buten-1-ol/ $\mathrm{H}_{2} \mathrm{O}_{2}=1: 1$, the solvent (methanol) concentration $40 \mathrm{wt} \%$, the catalyst concentration $0.1 \mathrm{wt} \%$ and the reaction time of $180 \mathrm{~min}$. The products were analyzed quantitatively by means of gas chromatography on a FOCUS apparatus (Thermo) with a flame-ionization detector (FID). A Quadrex capillary column $(30 \mathrm{~m} \mathrm{x}$ $250 \mu \mathrm{m} \times 0,25 \mu \mathrm{m}$ ) was used. An uncreated hydrogen peroxide was determined by an iodometric method. After the calculation of the mass balance for each of the syntheses, the main functions describing the process: the selectivity of the transformation to 2,3-epoxybutan-1-ol in relation to the consumed 2-buten-1-ol ( $\left.\mathrm{S}_{\mathrm{EB} / \mathrm{CRA}}\right)$ and the selectivity of the transformation to the organic compounds in relation to the consumed $\mathrm{H}_{2} \mathrm{O}_{2}\left(\mathrm{~S}_{\mathrm{org} / \mathrm{H} 2 \mathrm{O} 2}\right)$ have been determined.

\section{RESULTS}

In the epoxidation of 2-buten-1-ol over the Ti-MCM-41 and Ti-MCM- 48 catalysts, the major reaction product is 2,3-epoxybutan-1ol (EB), however, the other products are formed depending on the applied technological parameters. The main side reaction is the hydration of 2,3epoxybutan-1-ol to 1,2,3-butanotriol. The other side products of the process are presented in Scheme 1. These products include crotonaldehyde, crotonic acid, dimethoxybutane-1-ol and ethers. All the by-products were identified by the GC/MS method and quantitatively established by the GC method.

The effect of the temperature on the course of epoxidation of 2-buten-1-ol over the Ti-MCM-41 and TiMCM-48 catalyst was investigated in the temperature range of $20-120^{\circ} \mathrm{C}$ (Fig. 1). It results from Fig.1 that the selectivity of the transformation to EB in relation to the consumed CRA amounts to $100 \mathrm{~mol} \%$ for the Ti-MCM- 


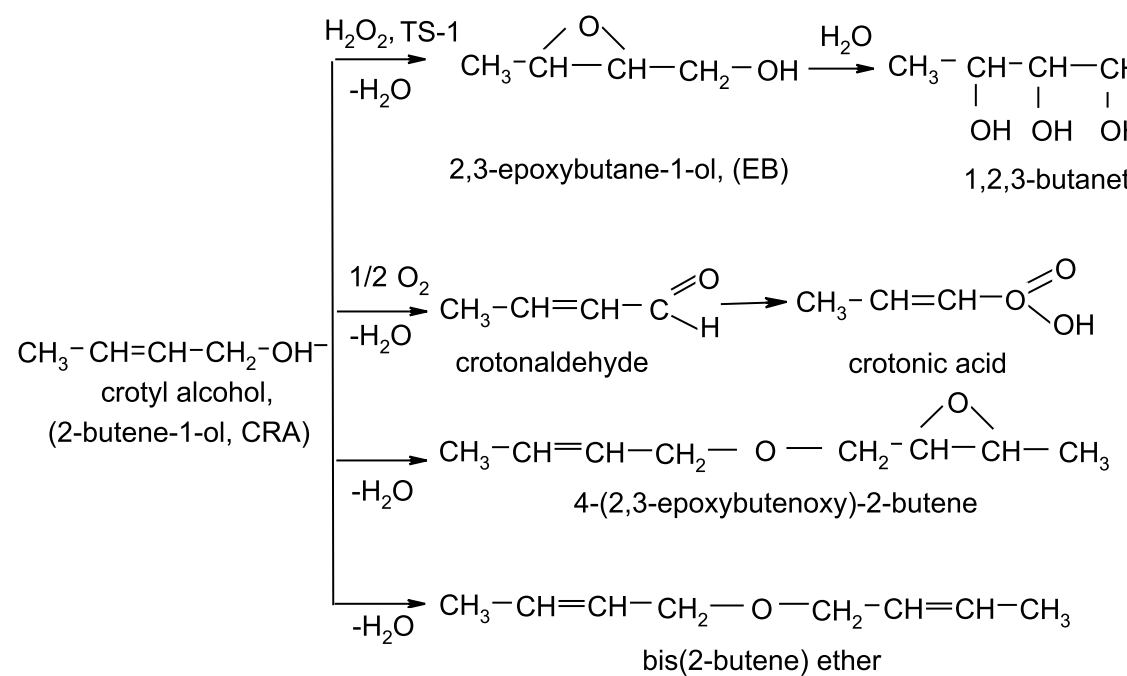

Scheme 1. The products of 2-butene-1-ol epoxidation

41 catalyst in the temperature range of $20-60^{\circ} \mathrm{C}$. A decrease of this function is observed at higher temperatures, which can be up to $10 \mathrm{~mol} \%$ at the temperature of $100^{\circ} \mathrm{C}$ or above this value. In the case of the Ti-MCM-48 catalyst, the reaction does not proceed at the temperature of $20^{\circ} \mathrm{C}$, however, the selectivity of the transformation to EB in relation to the consumed CRA amounts to 100 mol\% at the temperature of $40^{\circ} \mathrm{C}$. A further increase in the temperature causes a decrease of this function value up to $2 \mathrm{~mol} \%$ at $90^{\circ} \mathrm{C}$ or at higher temperature. A decrease of the selectivity of the transformation to EB in relation to the consumed CRA in the case of both catalysts is caused by the formation of the side products such as 1,2,3-butanotriol, crocrotonaldehyde and crotonic acid, and the ethers. 1,2,3-Butanotriol is formed with the selectivity of $50 \mathrm{~mol} \%$ at $120 \mathrm{oC}$ over the Ti-MCM-41 catalyst, whereas over the Ti-MCM-48 catalyst the selectivity amounting to about $80 \mathrm{~mol} \%$ at temperatures 80 and $100^{\circ} \mathrm{C}$, was achieved. In the case of the selectivity of the transformation to the organic compounds in relation to the consumed $\mathrm{H}_{2} \mathrm{O}_{2}$, an increase in the value of this function was observed for both catalysts during the elevation of the process temperature. The value of this function increases from $74 \mathrm{~mol} \%\left(20^{\circ} \mathrm{C}\right)$ to $77 \mathrm{~mol} \%\left(100^{\circ} \mathrm{C}\right)$ and then decreases to $57 \mathrm{~mol} \%\left(120^{\circ} \mathrm{C}\right)$ over the Ti-MCM-41 catalyst, whereas over the Ti-MCM-48 catalyst from 0 $\mathrm{mol} \%\left(20^{\circ} \mathrm{C}\right)$ to $95 \mathrm{~mol} \%$ at $100^{\circ} \mathrm{C}$ and then decreases to $86 \mathrm{~mol} \%\left(120^{\circ} \mathrm{C}\right)$.

The most advantageous temperature of epoxidation over the Ti-MCM- 41 catalyst amounts to $60^{\circ} \mathrm{C}$. For this temperature the selectivity of the transformation to $\mathrm{EB}$ in relation to the consumed CRA reaches $100 \mathrm{~mol} \%$ at the CRA conversion of $74 \mathrm{~mol} \%$, the $\mathrm{H}_{2} \mathrm{O}_{2}$ conversion of 96 $\mathrm{mol} \%$ and the selectivity of the transformation to the organic compounds in relation to the consumed $\mathrm{H}_{2} \mathrm{O}_{2}$ was $79 \mathrm{~mol} \%$. However, the studies performed with the Ti-MCM-48 catalyst demonstrate that the most advantageous temperature is $40^{\circ} \mathrm{C}$. The selectivity to $\mathrm{EB}$ in relation to the consumed CRA at this temperature amounts to $100 \mathrm{~mol} \%$ at the CRA conversion of $77 \mathrm{~mol} \%$, the $\mathrm{H}_{2} \mathrm{O}_{2}$ conversion of $90 \mathrm{~mol} \%$ and the selectivity of the transformation to the organic compounds in relation to the consumed $\mathrm{H}_{2} \mathrm{O}_{2}$ was $86 \mathrm{~mol} \%$.
The studies of the influence of the CRA/ $\mathrm{H}_{2} \mathrm{O}_{2}$ molar ratio on the CRA epoxidation were carried out in the range from $0.5: 1$ to $5: 1$ at the temperature of $60^{\circ} \mathrm{C}$ over the Ti-MCM- 41 catalyst and at $40^{\circ} \mathrm{C}$ over the Ti-MCM48 catalyst (Fig. 1b). These studies have demonstrated that the selectivity of the transformation to EB in relation to the consumed CRA does not undergo a change and amounts to $100 \mathrm{~mol} \%$ along with an increase in the molar ratio of reagents when the reaction is carried over the TiMCM-41 catalyst. The selectivity of the transformation to the organic compounds in relation to the consumed $\mathrm{H}_{2} \mathrm{O}_{2}$ increases from $50 \mathrm{~mol} \%\left(\mathrm{CRA} / \mathrm{H}_{2} \mathrm{O}_{2}=0.5: 1\right)$ to $100 \mathrm{~mol} \%$ for $\left(\mathrm{CRA} / \mathrm{H}_{2} \mathrm{O}_{2}=5: 1\right)$. The reaction does not proceed over the Ti-MCM-48 catalyst when the molar ration of CRA/ $\mathrm{H}_{2} \mathrm{O}_{2}$ is equal to $0.5: 1$. The selectivity of the transformation to EB in relation to the consumed CRA reaches $100 \mathrm{~mol} \%$ for the equimolar ratio of the reagents. However, the selectivity of the transformation to the organic compounds in relation to the consumed $\mathrm{H}_{2} \mathrm{O}_{2}$ for the TiMCM- 48 catalyst amounts to $0 \mathrm{~mol} \%$ at the molar ratio of $\mathrm{CRA} / \mathrm{H}_{2} \mathrm{O}_{2}=0.5: 1$, and subsequently the selectivity reaches $100 \mathrm{~mol} \%$ at the $\mathrm{CRA} / \mathrm{H}_{2} \mathrm{O}_{2}$ molar ratio of 5:1.

The molar ratio of $\mathrm{CRA} / \mathrm{H}_{2} \mathrm{O}_{2}=1$ was recognized as the most advantageous process in the process. However, in the case of the Ti-MCM- 41 catalyst, the low CRA/ $\mathrm{H}_{2} \mathrm{O}_{2}$ molar ratios are associated with a risk of activity loss by the catalyst, because $\mathrm{H}_{2} \mathrm{O}_{2}$ may form the soluble complexes with $\mathrm{Ti}$ occurring in the catalyst structure. Simultaneously, the process proceeds as the homogenous catalysis. The CRA conversion of about $75 \mathrm{~mol} \%$ with the $\mathrm{H}_{2} \mathrm{O}_{2}$ conversion of about $93 \mathrm{~mol} \%$ was achieved for both catalysts under the most favorable conditions.

The effect of solvent (methanol) concentration was studied in the range of $5-90 \mathrm{wt} \%$, at the molar ratio of CRA/ $\mathrm{H}_{2} \mathrm{O}_{2}=1: 1$, the temperature of $60^{\circ} \mathrm{C}$ in the presence of the Ti-MCM-41 catalyst, whereas at $40^{\circ} \mathrm{C}$ in the presence of the Ti-MCM-48 catalyst (Fig.2a). The selectivity of the transformation to EB in relation to the consumed CRA, it increases from $77 \mathrm{~mol} \%$ to $100 \mathrm{~mol} \%$ over the TiMCM-41 catalyst during an increase of solvent concentration from 5 to $40 \mathrm{wt} \%$. A further elevation of the solvent concentration does not cause the changes of this function. The selectivity of the transformation to the organic compounds in relation to the consumed $\mathrm{H}_{2} \mathrm{O}_{2}$ over the Ti- 
a)

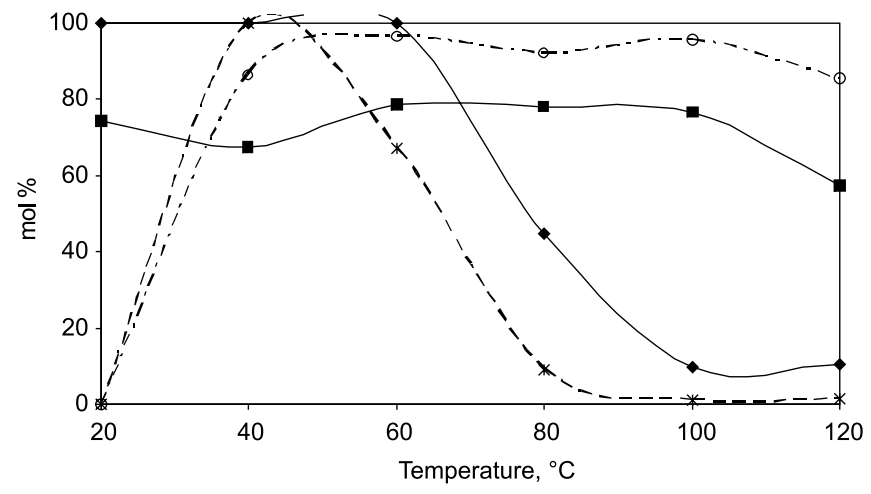

b)

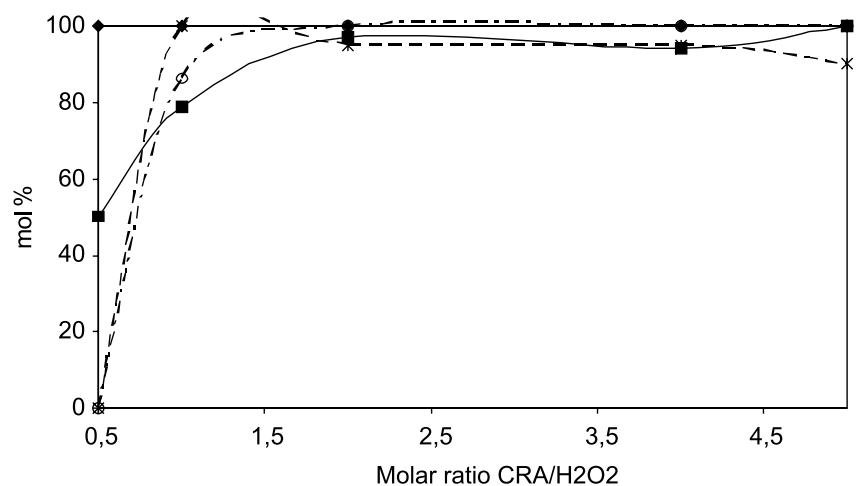

Figure 1. a) the influence of the temperature on the epoxidation of crotyl alcohol: - selectivity to 2,3epoxybutane-1-ol (Ti-MCM-41), - - the selectivity of the transformation to organic compounds in relation to the hydrogen peroxide consumed ( $\mathrm{Ti}$ MCM-41), * - the selectivity to 2,3-epoxybutane1-ol (Ti-MCM-48), O - the selectivity of the transformation to organic compounds in relation to the hydrogen peroxide consumed (Ti-MCM-48), b) the influence of the molar ratio $\mathrm{AKR} / \mathrm{H}_{2} \mathrm{O}_{2}$ on the epoxidation of crotyl alcohol: - the selectivity to 2,3-epoxybutane-1-ol (Ti-MCM-41), - - selectivity of the transformation to organic compounds in relation to the hydrogen peroxide consumed (Ti-MCM-41), * - the selectivity to 2,3epoxybutane-1-ol (Ti-MCM-48), O - the selectivity of the transformation to organic compounds in relation to the hydrogen peroxide consumed ( $\mathrm{Ti}$ MCM-48)

MCM-41 catalyst increases from $80 \mathrm{~mol} \%$ at $5 \mathrm{wt} \%$ of methanol to $100 \mathrm{~mol} \%$ (at methanol content of $90 \mathrm{wt} \%$ ). In the case of the Ti-MCM-48 catalyst, the selectivity of the transformation to $\mathrm{EB}$ in relation to the consumed CRA is the highest in the range of methanol concentration of 5-40 wt $\%$, and subsequently it decreases to below $5 \mathrm{wt} \%$ in the range of higher concentrations. Despite the high conversion of CRA, the amount of EB in the postreactive mixture is small due to its reaction with methanol. The selectivity of the transformation to the organic compounds in relation to the consumed $\mathrm{H}_{2} \mathrm{O}_{2}$ varies in a similar way over the catalysts: Ti-MCM-48 and Ti-MCM41. In the range of methanol concentration of $60-90$ $\mathrm{wt} \%$, the selectivity amounts to $100 \mathrm{~mol} \%$. The most advantageous concentration of methanol in the presence of Ti-MCM-41 amounts to $40 \mathrm{wt} \%$. In this case, the only product is $\mathrm{EB}$, the CRA conversion amounts $74 \mathrm{~mol} \%$, whereas the conversion of $\mathrm{H}_{2} \mathrm{O}_{2}$ is $96 \mathrm{~mol} \%$, and the selectivity of the transformation to the organic compounds a)

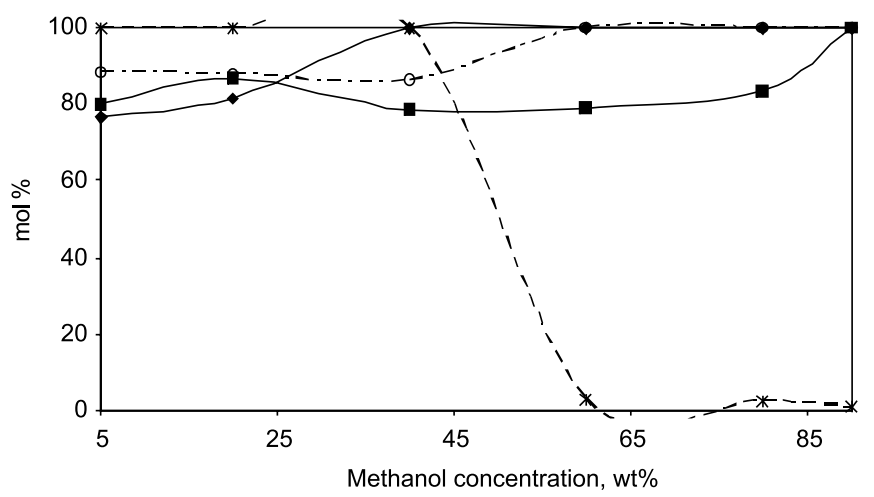

b)

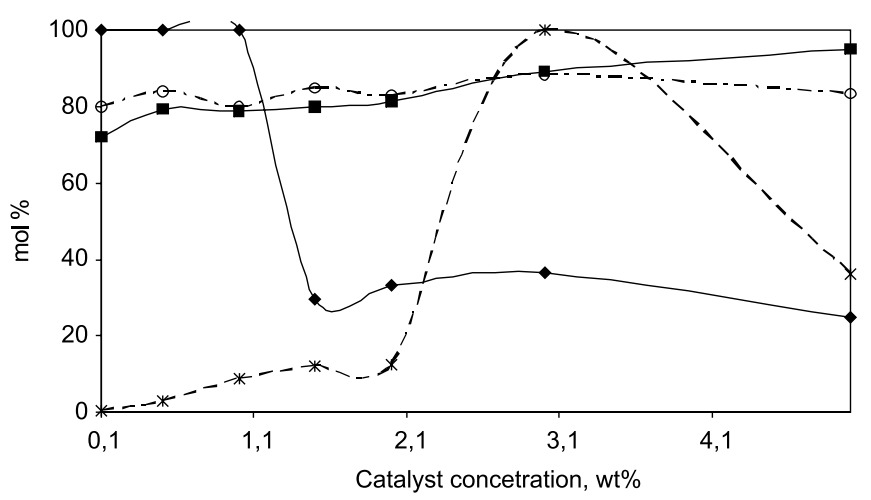

c)

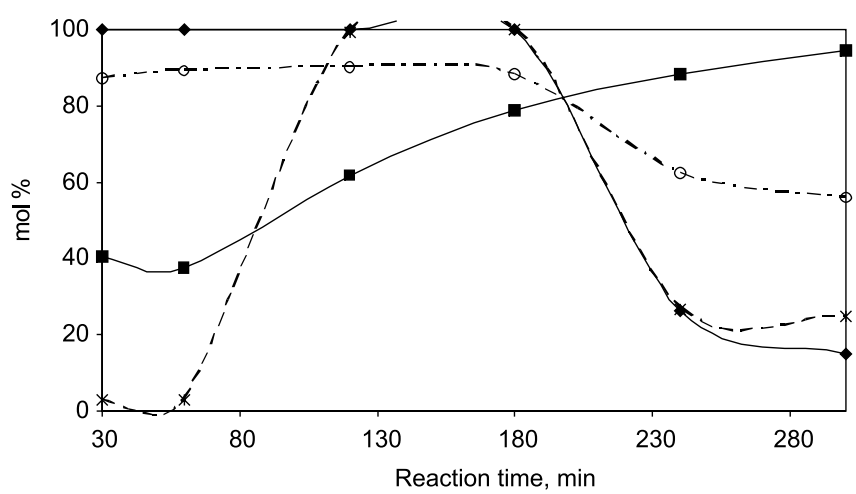

Figure 2. a) the influence of the solvent concentration on the epoxidation of crotyl alcohol - the selectivity to 2,3-epoxybutane-1-ol (Ti-MCM-41), - the selectivity of the transformation to organic compounds in relation to the hydrogen peroxide consumed (Ti-MCM-41), the selectivity to 2,3-epoxybutane-1ol (Ti-MCM-48), O - the selectivity of the transformation to organic compounds in relation to the hydrogen peroxide consumed (Ti-MCM-48), b) the influence of the TS- 1 catalyst concentration on the epoxidation of crotyl alcohol $\downarrow$ - the selectivity to 2,3-epoxybutane-1-ol (Ti-MCM-41), - - the selectivity of the transformation to organic compounds in relation to the hydrogen peroxide consumed (Ti-MCM-41), * - the selectivity to 2,3-epoxybutane1-ol (Ti-MCM-48), O - the selectivity of the transformation to organic compounds in relation to the hydrogen peroxide consumed (Ti-MCM-48), c) the influence of the reaction time on the epoxidation of crotyl alcohol: - the selectivity to 2,3epoxybutane-1-ol (Ti-MCM-41), $\mathbf{-}$ - the selectivity of the transformation to organic compounds in relation to the hydrogen peroxide consumed ( $\mathrm{Ti}$ MCM-41), * - the selectivity to 2,3-epoxybutane-1ol (Ti-MCM-48), O - the selectivity of the transformation to organic compounds in relation to the hydrogen peroxide consumed (Ti-MCM-48) 
in relation to the consumed $\mathrm{H}_{2} \mathrm{O}_{2}$ amounts to $79 \mathrm{~mol} \%$. The optimal concentration of methanol amounts to $5 \mathrm{wt} \%$ in the presence of the Ti-MCM-48 catalyst. The only product is also $\mathrm{EB}$, the CRA conversion amounts to $82 \mathrm{~mol} \%$, the $\mathrm{H}_{2} \mathrm{O}_{2}$ conversion is $93 \mathrm{~mol} \%$, and the selectivity of the transformation to the organic compounds in relation to the consumed $\mathrm{H}_{2} \mathrm{O}_{2}$ amounts to $88 \mathrm{~mol} \%$.

The effect of the concentration of the Ti-MCM-41 catalyst was studied at the temperature of $60^{\circ} \mathrm{C}$, at the molar ratio of CRA/ $\mathrm{H}_{2} \mathrm{O}_{2}=1: 1$, methanol concentration of 40 wt $\%$ and over the time of $180 \mathrm{~min}$. The obtained results are shown in Fig. 2b. These results demonstrated that along with an increase in the concentration of this catalyst, the selectivity of the transformation to EB in relation to the consumed CRA decrease from $100 \mathrm{~mol} \%(0.1 \mathrm{wt} \%$ of catalyst) to $25 \mathrm{~mol} \%$ ( $5 \mathrm{wt} \%$ of catalyst). At the highest concentration of the catalyst, the major reaction product is 1,2,3-butanetriol. The selectivity of the transformation to the organic compounds in relation to the consumed $\mathrm{H} 2 \mathrm{O} 2$ increases from $72 \mathrm{~mol} \%$ to $95 \mathrm{~mol} \%$ over the studied range of the catalyst concentrations. In the presence of Ti-MCM-48 the studies were carried out at the temperature of $40^{\circ} \mathrm{C}$, the equimolar ratio of the reagents, methanol concentration of $5 \mathrm{wt} \%$ and during the time of $180 \mathrm{~min}$. These studies have demonstrated that the highest selectivity of the transformation to EB in relation to the consumed CRA is achieved at the catalyst concentration of $3 \mathrm{wt} \%$, and the selectivity of the transformation to the organic compounds in relation to the consumed $\mathrm{H}_{2} \mathrm{O}_{2}$ practically does not undergo a change over the studied range of the catalyst concentrations and it amounts to about $85 \mathrm{~mol} \%$. After taking into consideration the obtained results, the concentration of $1 \mathrm{wt} \%$ was recognized as the optimal concentration of the Ti-MCM-41 catalyst. Under these conditions, the only reaction product is EB, the CRA conversion amounts to $74 \mathrm{~mol} \%$, whereas the conversion of $\mathrm{H}_{2} \mathrm{O}_{2}$ is $96 \mathrm{~mol} \%$, and the selectivity of the transformation to the organic compounds in relation to the consumed $\mathrm{H}_{2} \mathrm{O}_{2}$ reaches 79 mol\%. Hence, the concentration of $3 \mathrm{wt} \%$ was recognized as optimal in the presence of the Ti-MCM-48 catalyst. At this concentration the selectivity of the transformation to $\mathrm{EB}$ in relation to the consumed CRA amounts to $100 \mathrm{~mol} \%$, the CRA conversion is $82 \mathrm{~mol} \%$, the $\mathrm{H}_{2} \mathrm{O}_{2}$ conversion $93 \mathrm{~mol} \%$, and the selectivity of the transformation to the organic compounds in relation to the consumed $\mathrm{H}_{2} \mathrm{O}_{2}$ amounts to $88 \mathrm{~mol} \%$.

The influence of the time of CRA epoxidation was investigated at the technological parameters recognized previously as the optimal for each of the catalysts (Fig 2c). These studies have demonstrated that the optimal times are similar and amount respectively, for Ti-MCM-41 $180 \mathrm{~min}$ and for Ti-MCM-48 - 120 - 180min. For these values of time, a high selectivity of the transformation to EB in relation to the consumed CRA of about $100 \mathrm{~mol} \%$ is achieved for both catalysts. In this case, the selectivity of the transformation to the organic compounds in relation to the consumed $\mathrm{H}_{2} \mathrm{O}_{2}$ amounts to $79 \mathrm{~mol} \%$ over the Ti-MCM-41 catalyst, whereas over the Ti-MCM-48 the selectivity reaches about $90 \mathrm{~mol} \%$.

\section{CONCLUSION}

The optimal parameters of the epoxidation of 2-buten1-ol over the Ti-MCM-41 catalyst are as follows: the temperature of $60^{\circ} \mathrm{C}$, the molar ratio of $\mathrm{CRA} / \mathrm{H}_{2} \mathrm{O}_{2}=1: 1$, methanol concentration of $40 \mathrm{wt} \%$, the catalyst concentration $1 \mathrm{wt} \%$, and the time of the process operation of $180 \mathrm{~min}$. For the process carried out over the Ti-MCM-48 catalyst, the optimal technological parameters are as follows: the temperature of $40^{\circ} \mathrm{C}$, the molar ratio of CRA/ $\mathrm{H}_{2} \mathrm{O}_{2}=1: 1$, methanol concentration of $5 \mathrm{wt} \%$, the catalyst concentration $3 \mathrm{wt} \%$, and the time of the process duration of $120 \mathrm{~min}$. The differences in the values of the optimal parameters for both catalysts may results from the differences in their structure, mainly with differences in the accessibility to the active sites. Despite the different parameters, the values of the functions describing the process are similar. The selectivity of the transformation to EB in relation to the consumed CRA amount to 100 mol\% for both cases.

\section{LITERATURE CITED}

(1) Ciesla U., Schüth F.: Ordered mesoporous materials, Microporous and Mesoporous Materials, 1999, 27, 131.

(2) Öye G., Sjöblom J., Stöcker M.: Synthesis, characterization and potential applications of new materials in the mesoporous range, Adv. Coll. Inter. Sci., 2001, 89 - 90, 439.

(3) Anderson M.: Simplified description of MCM-48, Zeolites, 1997, 19, 220.

(4) Kumar D., Schumacher K, Hohenesche C. F., Grün M., Unger K.: MCM-41, MCM-48 and related mesoporous adsorbents: their synthesis and characterization, Coll. Surf. A: Phys. Eng. Aspects, 2001, $187-188,109$.

(5) Tanner D.: Stereocontrolled synthesis via chiral aziridines, Pure\&Appl. Chem., 1993, 65, 1319.

(6) Kobayashi M., Wang W., Tsutsui Y., Sugimoto M., Murakami N.: Absolute Stereostructure and Total Synthesis of Leptomycin B, Tetrahedron Lett., 1998, 39, 8291.

(7) Nishi K., Yoshida M., Fujiwara D., Nishikawa M., Horiniuchi S., Beppu T.: Leptomycin B targets a regulatory cascade of crm1, a fission yeast nuclear protein, involved in control of higher order chromosome structure and gene expression, J. Biol. Chem., 1994, 269, 6320.

(8) Jang B. Ch., Munoz - Najar U., Paik J. H., Claffey K., Yoshida M., Hla T.: Leptomycin B, an Inhibitor of the Nuclear Export Receptor CRM1, Inhibits COX-2 Expression, J. Biol. Chem., 2003, 278, 2773.

(9) Shao H., Zhu Q., Goodman M.: A New Asymmetric Synthesis of .alpha.-Methylcysteines via Chiral Aziridines, J. Org. Chem., 1995, 60, 790.

(10) Grün M., Unger K. K., Matsumoto A., Tsutsumi K.: Novel pathways for the preparation of mesoporous MCM41 materials: control of porosity and morphology, Microporous and Mesoporous Materials, 1999, 27, 207.

(11) Schumacher K., Grün M., Unger K. K.: Novel synthesis of spherical MCM-48, Microporous and Mesoporous Materials, 1999, 27, 201. 